\title{
The Determinants of Rural Households Food Security and Coping Strategies: The Case of Meta District, East Hararghe Zone of Oromia National Regional State of Ethiopia
}

\author{
Abdi Yusuf Mohammed* \\ Department of Rural Development and Agricultural Extension, Oda Bultum University, Ethiopia \\ Dr. Eric Ndemo \\ Department of Rural Development and Agricultural Extension, Haramaya University, Ethiopia \\ Dr. Chanyalew Seyoum \\ Department of Rural Development and Agricultural Extension, Haramaya University, Ethiopia
}

\begin{abstract}
Africa is making slow progress in achieving international hunger targets. About 795 million people were chronically malnutrition in worldwide of which 780 million were in developing countries especially in SSA. Recent revised humanitarian requirements documents estimate that 9.7 million people in Ethiopia were in need of emergency food assistance and 420,000 children were requiring treatment for severe acute malnutrition in 2016. So, understanding the major determinants of food security is primary importance in choosing appropriate interventions for addressing the problem of food insecurity. Data on demographic and socio-economic characteristics and institutional aspects were collected from 149 households through interview schedule, key informant interviews and focus group discussion. Descriptive statistics, inferential statistics and Logit model were used for data analysis. The survey results indicate that $53.02 \%$ of the respondents were food secure, while $46.98 \%$ were food insecure. Results also indicate that there was a significant mean difference at different level of significance between the food secure and food insecure households in terms of age, sex, family size, dependency ratio, educational levels, size of cultivated land, livestock ownership excluding oxen own, off/non-farm income, cash crop produces, fertilizer user, contact with development agents, improve seeds user, distance to the nearest market and access to credit. Among 16 explanatory variables included in the logit model, 8 of them were found to be significant at different probability level, including sex, size of cultivated land and livestock ownership excluding oxen were positive effect on food security whereas, age, family size, dependent ratio, access to the nearest market and access to credit had negative effect on food security. The major portion of this study was about the determinants of rural households' food security, it has been realized that the determinants of rural households' food security were broad, interrelated and varies. These can be addressed by a wide comprehensive intervention from different angles of social aspects.
\end{abstract}

Keywords: Food security, determinants, rural households, coping strategies, Meta, logistic regression, Ethiopia. DOI: $10.7176 /$ IAGS/89-01

Publication date: January $31^{\text {st }} 2021$

\subsection{Background to the Study}

Africa is making slow progress in achieving international hunger targets. About 795 million people were chronically malnutrition in worldwide of which 780 million were in developing countries especially in SSA [1]. Food insecurity has become one of the defining features of rural poverty in Ethiopia particularly, in drought prone areas. The problem of food insecurity is undermining people's health, productivity, and often their very survival. Ethiopia, the second populous nation in Africa, is also out of the total population of the country, $81 \%$ of the population lives in rural areas [2]. The foundation of its economic growth is agriculture which plays an important role in the national economy [3]. It accounts about $43 \%$ of the total GDP, employing and supporting about $85 \%$ of the total population and accounts for about $90 \%$ of the exports but its productivity and performance in terms of feeding the country's population which is growing at $2.6 \%$ per annum is dismal [4].

About $10 \%$ of Ethiopia's citizens are chronically food insecure and this figure rises to more than $15 \%$ during frequent drought years. 2.7 million People were requiring emergency food assistance in 2014 and 238,761 children were requiring treatment for severe acute malnutrition in 2014 [5]. Recent revised humanitarian requirements documents estimate that 9.7 million people in Ethiopia were in need of emergency food assistance and 420,000 children were requiring treatment for severe acute malnutrition in 2016 [6].

\subsection{Statement of the Problem}

A lot of resources are being channeled towards programs aimed at eradicating food insecurity and poverty by various international organizations and governments of developing nations including Ethiopia. The Government 
of Ethiopia, WFP and development partners work together to increase families' long term resilience to food shortages. For instance, in 2005 Productive Safety Net Program (PSNP) was established and aimed at enabling the rural poor facing chronic food insecurity to resist shocks, create assets and become food self sufficient. In this year the program commenced by covering four regions of the country (Tigray, Amhara, Oromiya and SNNPR) aiming to reach more than 1.6 million households (5 million people) in 263 districts identified as chronically food insecure areas [7-9]. By the end of 2010, the number of peoples whose PSNP beneficiaries had reached over 7.8 million spanning over 300 districts in eight regions across the country [10].

Despite the effort made by the Government of Ethiopia, World Food Program and development partners' food insecurity problem remains a challenge in Ethiopia in several and particular in Meta district. In line to this Meta district is one of the food insecure districts which government is taken as a pilot district for the implementation of PSNP in 25 Kebeles by having 33975 numbers of beneficiaries starting from 2006 up to 2015. But now, in 28 Kebeles by having 23833 numbers of beneficiaries' and also here is high problem of food insecurity in the district. In each year, Meta district is identified among food insecure districts of the east Hararghe zone. There is high level of rural urban migration in search of employment [11].

Therefore, beside to participating peoples in PSNP it is important to understand the major determinant of food security at different level due to the Problem of food insecurity take particular forms in its extent, causes and consequences at different level of analyses. Thus, the main reasons that the researcher has taken this study which is determinants of rural households food security and coping strategies in Meta district is to distinguish whether the above mention problems are the really true applicable problems in the study area or not and also depending on the results giving clue for development policy as they work on that to improve food security. In addition to this the study was initiated to identify the food security status, determinants and coping strategies employed by households during food shortages time in the study area.

\subsection{Objective of study}

To assess determinants of rural households' food security and copping strategies in Meta district of East Hararghe Zone, Oromiya National Regional state of Ethiopia.

Research questions

1. What is the status of food security in the study area?

2. What are the major determinants of food security status among the rural household?

3. What coping strategies do vulnerable households employ to cope with food shortage?

\subsection{Significance of the Study}

This study has analyzed the determinants of rural households' food security and coping strategies at household level. Because, it is important to provide information how effective measures will be made to implement appropriate strategies and enhance food security. Besides, the output of this research may help to provide strategic information which enables policy makers to develop functional intervention for dealing and support solution of households in dealing with food insecurity problem in the study area. It gives insight for researchers and students interested in similar research theme for further investigation in other areas. And also the study may help to identify the different coping strategies and information gap in order to make interventions appropriate to the area.

\section{Research methodology}

\subsection{Description of the Study Area}

The study was conducted in Meta district, which is one of the twenty (20) districts of eastern Hararghe zone of Oromia National Regional State. The district is located in northern part of east Hararghe zone at $9^{0} 07^{\prime}$ and $9^{0} 32^{\prime}$ north latitude and $41^{0} 29^{\prime}$ and $41^{\circ} 44^{\prime}$ east longitude. It is bordered by four-district of eastern Hararghe zone (Kersa, Gorogutu, Deder and Bedeno) and two regional boundaries, namely Somali National Regional State and Dire Dawa Provisional Administrative Council. At the present time the District is sub divided into thirty nine (39) rural and three (3) urban Keble's. The administrative center of the district is Chelenko, located in a distance of about $84 \mathrm{~km}$ from Harar town along the main road to Addis Ababa. Based on temperature, rainfall and altitude differentials, three agro ecological zones are distinguished, namely lowland, mid-land and highland, which account for 28.2, 43.6 and $28.2 \%$ of the total area of the district, respectively. Lowland is an agro-ecological zone that refers to areas less than 1500 meter above sea level (m.a.s.l), with temperature ranging over $20^{\circ} \mathrm{C}$ and annual precipitation less than $600 \mathrm{~mm}$. Mid-land refers to areas of altitude range of 1500 to 2300 m.a.s.1, its temperature between $16^{\circ} \mathrm{C}-20^{\circ} \mathrm{C}$ and annual precipitation in the range of $800-1000 \mathrm{~mm}$, and highland refers to areas of between 2300 and 2925 m.a.s.l, mean temperature of less than $16^{\circ} \mathrm{C}$ and annual precipitation of 1400 $\mathrm{mm}$ [12]. Rainfall in the study District is characterized by a bimodal and erratic distribution pattern, which gives two cropping seasons of Meher (from July to the end of September) and the Belg (end of February to the middle of May). The annual average rainfall ranges from $600 \mathrm{~mm}$ to $1200 \mathrm{~mm}$. The mean annual temperature of the area 
ranges between $16.25^{\circ} \mathrm{C}$ the highest temperature usually occurs during February and March and sometimes goes up to $35^{\circ} \mathrm{C}$. The lowest temperature is about $12^{\circ} \mathrm{C}$ which occurs during the months of July and August. The average precipitation is generally considered adequate for rain-fed agriculture. But uneven distribution, specially, in the low land and midland of the District, has resulted in frequent crop failure [13].

The total population of Meta district is 200686 of which 94978 were men and 105708 were women. Mixed farming system (crop-livestock integration) prevails as a dominant economic activity in the district. Depending on the agro-ecological location, households in the study area produce varying degree of mix of cereals, pulses, oil seeds, and livestock Some households also grow cash crops such as coffee and vegetables to a lesser extent with almost all households producing chat.

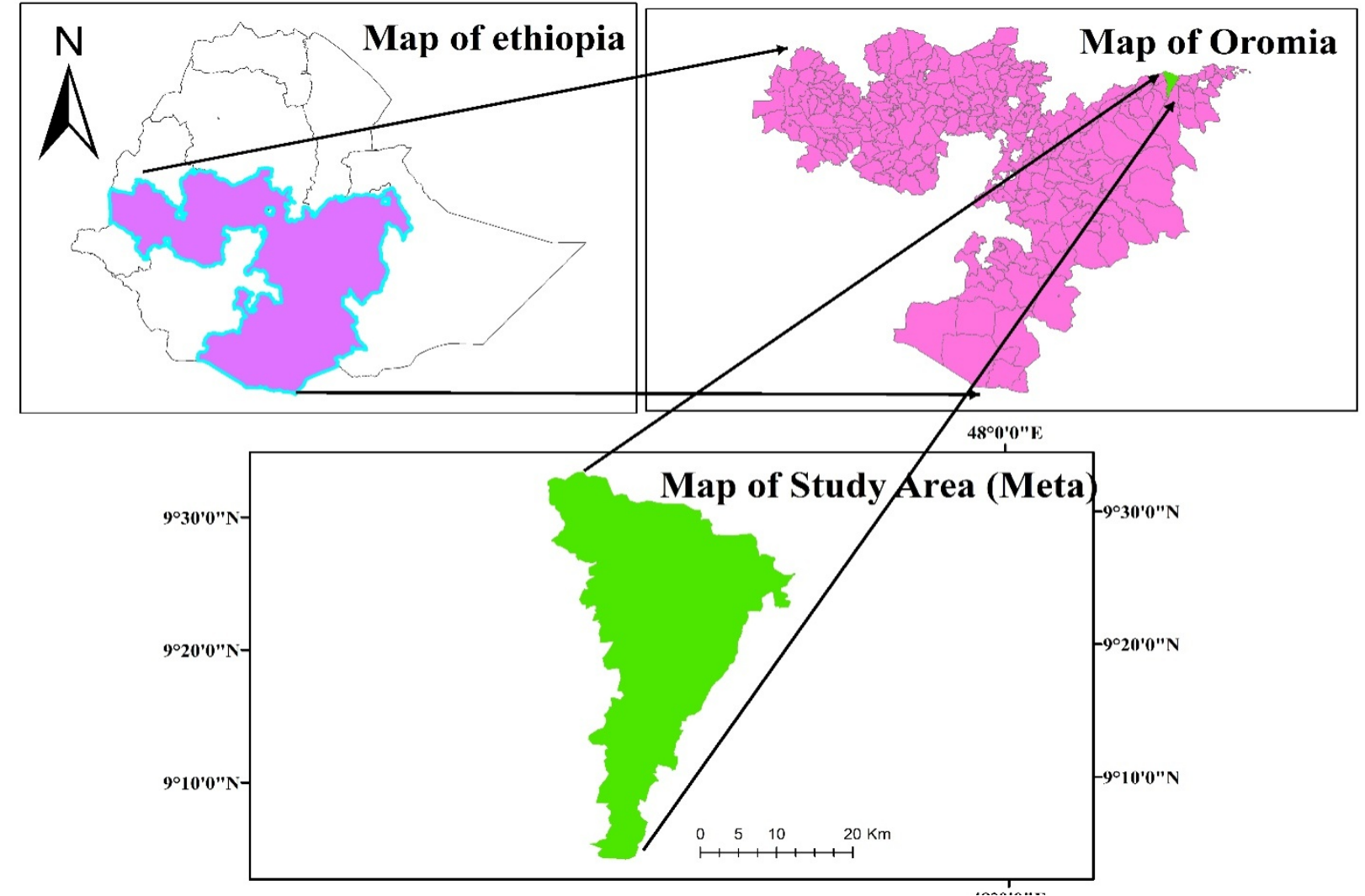

Figure 1: Map of the study area, 2016

\subsection{Sampling Technique}

The study employed multi-stage sampling techniques to select the representative samples. First, the rural kebeles of Meta district were stratified into three based on agro-ecology (highland, midland and lowland). Secondly, from each agro-ecological zone one rural kebele was selected by using simple random sampling. Finally, from the selected kebeles the required representative sampled households were randomly selected based on proportional to size of populations. The desired number of sample household was determined by using Yamane formula [14]. To determine the required sample size at $95 \%$ confidence level, with a 0.5 degree of variability and $8 \%$ level of precision.

$n=\frac{N}{1+N(e)_{2}} \quad n=\frac{3394}{1+3394(0.8)_{2}}=149.37$

Where: $\mathrm{n}=\left(n_{1}+n_{2}+n_{3}\right)$ the total number of sampled households $n_{1}, n_{2}$, and $n_{3}$ are the number of households proportionally selected from each of the three selected kebeles. $\mathrm{N}=$ Total number households of the three selected kebeles and $\mathrm{e}=$ level of precision. When calculated by Yamane formula $\mathrm{n}=149.37$ which will be $\approx 149$. Then accordingly the sample sizes of 149 rural households were selected randomly from the selected three (3) rural kebeles, namely Bakelcha Oromia, Bikiye Number one and Waltaya. 
Table 1: Total number of households by kebeles and their respective sample size

\begin{tabular}{lll}
\hline Name of the kebeles & Total number of households & Sampled households \\
\hline Bakkalcha Oromia & 1087 & 48 \\
Bikkiye no. 1 & 1138 & 50 \\
Waltaha & 1169 & 51 \\
\hline Total & 3394 & 149
\end{tabular}

Source: own computation from district data, 2017

\subsection{Method of Data Collection}

Both quantitative and qualitative types of data were used for this study which was collected from both primary and secondary sources. The primary data were gathered using structural interview schedule, key informant interview and focus groups discussion.

\subsection{Methods of Data Analysis}

In order to achieve the stated objectives of the study, the survey data were edited, coded, organized and analyzed using descriptive, inferential statistics and logit model using STATA version 13. Quantitative data were coded and analyzed by using different statistical techniques. Logit model was used to identify the determinants of the rural household food security and also the study used the direct survey of household consumption to measure the household food security status. Narration and conceptual explanation was employed to analyze data having qualitative nature such as coping strategies employed by sample households during food shortages and other supplementary information for quantitative data which were collected using focus group discussions and key informant interviews. Descriptive summaries of coping strategies data were expressed in \%ages and frequency distributions.

\subsection{Variables}

\subsubsection{Dependent variable}

Food security status, which is dependent variable for the logit analysis, is a dichotomous variable representing 1 for food secure and 0 for food insecure.

\subsubsection{Independent variables}

In this study the independent variables are the potential explanatory variables that can influence state of household food security in the study area. Based on the review of literature and the past research findings the following sets of variables were selected to identify the potential determinants of household food security in the study area.

\subsection{Result and discussion}

\subsubsection{Households Food Security Status}

The survey result in Table 3 indicates that, from all respondent 79 households met the minimum subsistence requirement per AE per day of 2,200 Kca

Table 2: Energy consumption in kcal per AE/day for the sample households

\begin{tabular}{|cccc|}
\hline Energy consumption & Food secure & Food insecure & Total \\
per AE in $(\mathrm{kcal})$ & $(\mathrm{N}=79)$ & \multicolumn{2}{c|}{$(\mathrm{N}=70)$} \\
\hline Minimum & 2233.57 & 1051.33 & 1051.327 \\
Maximum & 3520.40 & 2086.88 & 3520.40 \\
Mean & 2530.74 & 1847.8 & 2209.89 \\
Standard Deviation(SD) & 311.35 & 197.95 & 431.65 \\
\hline
\end{tabular}

Note: $* * *$ Significant at $1 \%$ probability level

Source: survey result, 2017

\subsubsection{Demographic and Socio-economic Characteristics}

Age of the household head: According to the survey results (as shown in Table 4) the age composition of the sampled households indicates that, the mean age of the total sampled respondents' household heads was 42.72 years. Moreover, the mean age difference between the food secure and insecure groups was found to be statistically significant at $1 \%$ probability level. This indicates that, the mean age of the food secure is lower than the food insecure. This means food secure household heads are in a relatively good position to manage their resources and become more productive than their counter parts.

Family size: Family size is one of an important variable, which determines the state of household food security status. As many earlier researcher hypothesized, the family size was considered as one of the most influential variables that could have dramatic impact on food security status of the households. The proportion of sampled 
households in becoming food secure increases as the family size decreases. The result in (Table 4) shows that, the overall mean family size of the sampled respondents by AE was 4.88. The mean family size of food secure and insecure households was found to be 3.96 and 5.91. In line with this result, the distribution of the sample households with regard to family size showed that, there was found statistically significant mean difference between the food secure and insecure sample households at one \% probability level. This shows the mean family size of food secure households was lower than the mean family size of the households' food insecure, on the basis this result, as the family size increases, the probability of the households to be food secure decreases.

Dependency ratio: The descriptive result part showed that, the overall mean dependency ratio of the sampled households was 1.23. The mean dependency ratio of food secure households was 0.81 and 1.71 for food insecure households (Table 4). Therefore, statistical analysis from the survey data revealed that there was statistically significant mean difference of the dependency ratio between food secure and food insecure households at one $\%$ probability level.

Education levels of HH heads: The educational level of the household head is an important human capital which is expected to affect food security status of households' positively. That is, the more the educational level of the household head, the more the possibility of household to diversify their livelihood so that the more possibility the household to become food secure. The survey results presented in Table 4 shows that, the mean educational level of the total sampled household heads was 1.94. The statistical analysis indicated that there was a statistically significant mean difference in terms of education level of the household heads between the food insecure and food secure households at one \% probability level.

Cultivated land size: Cultivated land is one of an important resource expected to be associated with food security status. That is households with large cultivated land will be more likely to be food secure than households with small cultivated land. As shown in Table 4, the mean cultivated land of the total sampled households was 0.29 , whereas the mean cultivated land holding for the food secure and insecure were 0.36 and 0.20 respectively. Thus, the result shows that there was statistically significant difference between food insecure and food secure households in their mean cultivated land at one $\%$ probability level. Similar result was reported by the findings of [15].

Livestock ownership: Livestock ownership refers to total livestock holding of households. In table 4 shows over all households on average owned 3.95 TLU. A considerable difference was obtained between food secure and food insecure households with average livestock holdings of 4.67 TLU and 2.38 TLU respectively. This difference was also found to be statistically significant at $1 \%$ probability level using an independent sample ttest (Table 4).

The number of oxen owned: As shown on Table 4, the mean number of oxen owned by the sampled households was less than the minimum traction power needed for crop production which is 0.60 . Consequently, the surveyed households were asked whether they were using oxen for cultivation or not, and if they use, how to access additional ox or oxen needed for their crop production activities. As they were response during survey, many of the sample households were not using oxen for cultivation either because the topography of their land is not convenient or they have small land holding or the land totally covered by perennial crop. In addition, different questions were also asked, in order to know how household's access additional ox owned for their crop production activities. A variety of traditional arrangements were used among the sample households in order to fulfill the minimum traction power needed for crop production and to access additional ox/oxen to carry out agricultural activities. These include exchange of labour for ox, sharecropping, share of land, pulling resources together (mutual cooperation), borrowing, renting of oxen and seeking assistance or gift from relatives. Accordingly, one or combinations of these methods were used to ensure access to oxen by the households included in the study area. Mean difference was tested to check whether or not oxen ownership makes significant difference between the food secure and insecure household groups. The mean ox holding for food secure households was 0.67 whereas that of food insecure was 0.54 . The result disagrees with a priori expectation, as mean ownership of ox or oxen was not found to be statistically significantly different between the food secure and insecure households.

Off/non-farm income: The success of households and their members in managing food insecurity is largely dependent on their ability access to off-farm/non-farm job opportunities which leads to generate income in the study area [16-17]. The major sources of off/non-farm income of the sample households in the study were generated from petty trading; sell of charcoal, fire-wood and grass, daily labour, food aid and others. But, majority of the surveyed households did not participate in such activities because of limited opportunities. As shows in (Table 4) the sampled households who were engaged in off/nonfarm activities had generated a mean income of Birr 265.95. Food secure households had generated high mean income of about Birr 321.81, while food insecure households had generated a mean income of Birr 202.92. The t-test result shows that there was statistical significant difference between food insecure and food secure households at one \% probability level.

Distance to market center: The proximity to market center creates access to additional income by providing non-farm employment opportunities and easy access to inputs, transportation and even better prices for their 
product [18]. Therefore, it was expected that the households located near to market center have better chance to improve household food security status than those who are far from the market centers. In line with this, the result of descriptive analysis in Table 4 shows that the overall mean distance of the sample respondents to the nearest market was 5.85 and the mean distance for food secure and food insecure households to the nearest market from home is 5.04 and 6.77 respectively. The result of statistical test shows there was statistically mean difference between the food insecure and food secure households in the market centre distance at one $\%$ probability level.

Contact with the development agents: As shown in (Table 4), from the total respondent households the mean contacts of the sampled households were 0.91 . The mean contacts with development agents for food insecure and food secure households were 0.59 and 1.19. As this result show that all means were very low (i.e. mean of total respondents contact with development agent, mean of food insecure and food secure households contact with development agent).

Table 3: Descriptive statistics for continuous variables and food security status of HHs

\begin{tabular}{|c|c|c|c|c|}
\hline & $\begin{array}{c}\text { Food secure } \\
(\mathrm{N}=79)\end{array}$ & $\begin{array}{l}\text { Food insecure } \\
(\mathrm{N}=70)\end{array}$ & $\begin{array}{l}\text { Total } \\
(\mathrm{N}=149)\end{array}$ & t-value \\
\hline Variables & Mean(SD) & Mean(SD) & Mean(SD) & \\
\hline Age of HHHs & $37.82(10.9)$ & $48.25(11.3)$ & $42.72(12.1)$ & $5.78 * * *$ \\
\hline Family size & $3.96(1.27)$ & $5.91(1.69)$ & $4.88(1.77)$ & $8.05 * * *$ \\
\hline Dependence ratio & $0.81(0.52)$ & $1.71(0.88)$ & $1.23(0.84)$ & $7.74 * * *$ \\
\hline Education & $2.65(2.67)$ & $1.14(1.9)$ & $1.94(2.45)$ & $-3.91 * * *$ \\
\hline Cultivated land size & $0.36(0.08)$ & $0.2(0.09)$ & $0.29(0.12)$ & $-11.11 * * *$ \\
\hline Livestock holding & $4.67(2.09)$ & $2.38(0.99)$ & $3.95(2.02)$ & $-8.35 * * *$ \\
\hline Number of oxen & $0.67(0.64)$ & $0.54(0.69)$ & $0.6(0.67)$ & -1.06 \\
\hline Off/non-farm income & $321.8(292)$ & $202.9(198)$ & $162(258.5)$ & $-2.87 * * *$ \\
\hline Distance to market & $5.04(3.02)$ & $6.77(3.43)$ & $5.85(3.32)$ & $3.29 * * *$ \\
\hline Contact to development agent & $1.19(0.86)$ & $0.59(0.81)$ & $0.91(0.89)$ & $-4.39 * * *$ \\
\hline
\end{tabular}

Note: $* * *$ Significant at $1 \%$ probability level

Source: survey result, 2017

Sex of the household heads: As shown in Table 5, from the total of 149 sample households heads included in the survey $91.95 \%$ were male-headed and $8.05 \%$ were female-headed. Out of which nearly $97.47 \%$ of food secure households were male-headed and whereas only about $2.53 \%$ were female-headed. Therefore, As a result of the chi-square test showed that there is a significant difference between male-headed and female-headed households in their food security status at one \% probability level.

Cash crop produces: Agriculture is the main source of livelihood of the people in Meta district. The major growing crops in the district are sorghum, maize, wheat, sweet potato and Haricot bean. In addition to this, cash crops like of Chat, vegetables (tomato, onion, potato, etc), coffee and sum of cereal crops such as bean, chicken bean and haricot bean were the major cash crops growing in the study area. As earlier researcher hypothesized Cash crop production is one of a means of generating income which in turn leads to higher income, higher rate and intensity of use purchased inputs and higher yield is positively and strongly associated with improving food security status of the households. This means, households who produce cash crops becomes in a better position than those who didn't produce cash crops in their livelihood situations.

As shown in Table 5, from the total of 149 sample of respondents included in the survey $42.95 \%$ were cash crop producers and $57.05 \%$ were non producers. About $65.63 \%$ of food secure households and $34.38 \%$ of food insecure households were cash crop producers in the study area. The chi-square test showed that there is a significant difference between those household who produce cash crops and not cash crop producers' households in their food security status at one \% probability level.

Fertilizer use: The application appropriate of modern farm inputs such as, chemical fertilizers; improved seed verities and herbicides increase agricultural yields, food production and income even food security. For this reason, the Ethiopian farmers have been encouraged to adopt utilization of modern farm inputs. However, low income farmers fail to use expensive inputs since they do not afford the cost [19-20].

In the study area, chemical fertilizer (Dap and urea) and improved seed verities (maize, wheat and haricot bean) were considered. But, in the study area most farmers did not use the fertilizers due to fear of its costly, shortage of rain and excess of rain which leads to burden rather than benefit. As shown in the Table 5, from the total sampled households, the users of chemical fertilizers accounted for $48.32 \%$, while the non-users of chemical fertilizers accounted for $51.68 \%$. The proportion of chemical fertilizer users was $27.78 \%$ of the total sampled food insecure households. In addition to this; chemical fertilizer users accounted for about $72.22 \%$ of the total food secure households. Whereas, the proportion of non-users of chemical fertilizers out of the total sampled food secure and food insecure households were 35.06 and $64.94 \%$ respectively. Generally, the result of chisquire confirmed with statistical significant difference between food secure and food insecure households in 
terms of the use of chemical fertilizers at one \% probability level.

Improved seeds use: In study area, production of crops is constrained by different factors which include shortage of rain fail, scarcity of land and traditional way of cultivating land and as a result yield of the crops are very low. In order to overcome this problem the only means is appropriate application of modern farm inputs such as chemical fertilizers; improved seeds and herbicides which turns leads to increase productivity. Thus, improved seeds; particularly moisture stress resistant varieties can withstand drought and erratic rain distribution and increases productivity by boosting overall production, which in turn contributes to attaining food security at household level was hypothesized that using improved seeds have positive association with household food security [21].The proportion of farmers in the use of improved seed is higher among the food secure groups than the food insecure groups of farmers (see Table 5). The difference was observed between the two groups, it was statistically significant at one $\%$ probability level. From this result, therefore, it might be possible to declare that using improved seed may lead to positive association with household food security.

Participate in PSNP: As shown in Table 5, from the total of 149 sample households heads included in the survey 27.52 were participant in PSNP and $72.48 \%$ were non participant in PSNP. Out of which nearly $25.85 \%$ of food secure households were participant and $28.57 \%$ were non participant in productive safety net program. Therefore, As a result of the chi-square test showed that there is no significant difference between participant and non participant households in their food security status.

Access to credit: Participation in credit service helps the farmers to purchase agricultural inputs such as fertilizer, improved seeds, and others which in turn increase production and secure the calorie level of the households. The result in Table 5 shows that $15.19 \%$ of the food secures and $4.29 \%$ of the food insecure households had credit-service users. Accordingly, the statistical analyses showed that there is a significant difference at $5 \%$ probability level. From this result, therefore, it might be possible to say that participation in credit may leads to the probability that the households to be food security. Only about $10.07 \%$ of the total surveyed households had received credit while the rest of them did not receive any credit.

Table 4: Descriptive statistics for dummy variables and food security status of HHs

\begin{tabular}{|c|c|c|c|c|c|}
\hline & & $\begin{array}{c}\text { Food secure } \\
(\mathrm{N}=79)\end{array}$ & $\begin{array}{c}\text { Food insecure } \\
(\mathrm{N}=70)\end{array}$ & $\begin{array}{c}\text { Total HHs } \\
(\mathrm{N}=149)\end{array}$ & $\chi^{2}$-value \\
\hline Variables & Categories & Number $(\%)$ & Number $(\%)$ & Number (\%) & \\
\hline \multirow[t]{2}{*}{ Sex of the HHHs } & Male & 77(97.47) & $60(85.71)$ & $137(91.98)$ & $6.92 * * *$ \\
\hline & Female & $2(2.53)$ & $10(14.29)$ & $12(8.05)$ & \\
\hline \multirow[t]{2}{*}{ Cash crop produces } & Yes & $42(65.63)$ & $22(34.38)$ & $64(42.95)$ & $7.16^{* * *}$ \\
\hline & No & $37(43.53)$ & $48(56.47)$ & $85(57.05)$ & \\
\hline \multirow[t]{2}{*}{ Fertilizer user } & Users & $52(72.22)$ & $20(27.78)$ & $72(48.32)$ & $20.62 * * *$ \\
\hline & Non-users & $27(35.06)$ & $50(64.94)$ & $77(51.68)$ & \\
\hline \multirow[t]{2}{*}{ Improved seeds use } & Users & $55(69.62)$ & $26(37.14)$ & $81(54.36)$ & $15.78 * * *$ \\
\hline & Non-users & $24(30.38)$ & $44(62.86)$ & $68(45.64)$ & \\
\hline \multirow[t]{2}{*}{ Participate in PSNP } & Participant & $20(25.32)$ & $21(30.00)$ & $41(27.52)$ & 0.40 \\
\hline & Non participant & $59(74.68)$ & $49(70.00)$ & $109(73.15)$ & \\
\hline \multirow[t]{2}{*}{ Access to credit } & Users & $12(15.19)$ & $3(4.29)$ & $15(10.07)$ & $4.87 * *$ \\
\hline & Non-users & $67(84.81)$ & $67(95.71)$ & $134(89.93)$ & \\
\hline
\end{tabular}

Note: $* *$ and $* * *$ Significant at 5 and $1 \%$ probability level

Source: survey result, 2017

\subsection{Determinants of Food Security}

Age of the households head: This variable is a continuous explanatory variable which was hypothesized to have an influence on food security status. It was found to be negative and significant at five \% probability level. The negative sign shows that the probabilities that the household was food secure decreased as the age of household head increases. Other factors remaining constant, increased in the age of the household head by one year, decreased the probability for the household to be food secure by $2.4 \%$. The possible reason for such result might be that older age household head are less reactive to the changing production environment or they might have been victims of the shrinking land resources as a result of sharing to their landless children. Sex of the household head: In this study, sex of the head of the household was found statistically significant at five \% probability level and had positive relationship with the household food security status. The positive sign showed that male headed households were more likely to be food secure than female headed households. Remaining other variables constant, food security male headed households increased by $68.3 \%$ than female headed households. This means that, male headed households have more access to agricultural technologies, more labor power and farmland as compared to female headed households. Family size: It is an important variable which determines the state of household food security and it was found to be statistically significant at one \% probability level and has negative association with the household food security. The negative sign shows that a 
probability to be food secure decreases as family size in adult equivalent increases. Other variables remaining constant increase in the family size in adult equivalent by a unit, decreases the probability of the household to be food secure by $24.3 \%$. The possible reason for such result might be an increase in family size implies more mouth to be fed from the limited resources. This result was in conformity with the hypothesis of other works [22]. That is large family size has negative relationship with food security.

Dependence ratio: this variable was found statistically significant and negative relationship with the household food security status at five \% probability level. The negative sign indicates that being food secure decreases as dependency ratio increases. Other variables remaining constant, the probability of being food secure for a household decreases by $39.5 \%$ as dependent age groups ( $<15$ to $>65$ of age) increases by one unit. The way of life in the study areas promotes large family size due to majority of inhabitant were Muslims, which could expose the family to have high dependency ratio and probably be less food secure than those who have small family size who could have low dependency ratio. This result coincides with the hypothesis of other [23].

Size of cultivated land: size of cultivated land had statistically significant and positive relationship with the household food security status at one \% probability level. The positive sign shown that the probability that the household was food secure increased as cultivated land increases. This mean that the households with large cultivated land produce more for the household consumption and have better chance to be food secure than those having relatively small size of cultivated land. Other variables remaining constant, increased in size of cultivated land by one unit, increased the probability that the household was food secure by $44.5 \%$. This result coincides with the results of (Tewodros and Fikadu, 2014[24]. Livestock ownership excluding oxen: Livestock are important source of income, food and the cow dung also used to increase fertility of soil which in turn increases crop production. It was found statistically significant at one $\%$ probability level and positive relationship with the household food security status. The positive sign shows that the probabilities that the household was food secure increased as the number of livestock holding in TLU increase. This imply that, remaining other variable constant, increased in the number of livestock holding in TLU, increased the probability that the household was food secure by $43.7 \%$. The reason behind this explanation was the fact that, households with large number of livestock in TLU had better chance of earning more income from livestock product and also selling livestock itself. This turn helped households to buy foods when they faced shortage and ensure security of household. Distance to market: It had found statistically significant at five \% probability level and negative relationship with the household food security status. The negative sign shows that, as the distance of the household stretches away from the market, the probability that household to be food secure decreases. The marginal effect showed that, when the travel household's market distance increases by one unit, the probability the household to be food secure decreases by $10 \%$. The possible explanation for this would be the more the household nearest to market, the more accesses on off-farm/non-farm employment opportunities, transportation and even fare prices for their product. This in turn increases the probability to generate additional income and the ability to purchase grain for household consumption and indirectly increase food security status of households.

Access to credit: This variable was found statistically significant at five \% probability level with negative sign. The negative sign showed that, the households with more access to credit have the possibility to decrease the probability of being food secure. The result of this study reveals that, all other factors remaining constant, the marginal effect showed that, when the household with more access to credit increases by one unit, the probability of household to food security decrease by $67.7 \%$. The possible explanation behind this was credit burdens on households who access rather than benefiting them. Because, the households investing the credit in buying food consumption and other things, rather than investing in farm and non-farm activities and which enhance sustainable food security. Most respondents in the area profess Islam and credit is perceived by their religious faith as a gift and therefore paying credit with interest is seen by them as "haram". However, the result contradictory with its prior hypothesized [25].

\subsection{Coping Strategies Employed by Households during Food Shortage}

Sample households in the study area employed various coping mechanisms during food shortage. During interview period Households mentioned they used eleven (11) different coping mechanisms at the time of food shortage which includes; reduce number of meal, reduce quantity of meal, sale of livestock, borrow grain/cash, participation in pity trade, sale of fire wood and charcoal/grasses, ate less preferred food, receive food aid, purchase food on cash, migrate to other area to work and children discontinued from school.

As listed in (Table 7), the types of coping mechanisms employed by the household at the time of food shortage in the study area; about $60.40 \%$ of the total respondents and $40.51 \%$ of food secure and $82.86 \%$ of food insecure households were reducing the number of meals. The second coping mechanisms commonly employed by respondents were reducing quantity of meal. Which is about $58.39 \%$ of the total respondents and $40.51 \%$ of food secure and $78.57 \%$ of food insecure households were reducing the quantity of meal. The results from the focus group discussions point out that almost all family members except children chewed chat to reduce pain of hunger/in response to the part of brain that unleashes hunger. Due to this reason people in the study area 
don't perceive chat as drag. In line with this, both reducing numbers and quantity of meal were the common copping mechanism in the study area and also as a result from focus group discussions showed that at the initial stages of food shortage, with exception of children practice reduction of food portions both by quantity and number of meals. But, when the period of the food shortage escalates then children are also forced to skip and reduce food as coping strategies.

Another important coping mechanism employed by farmers was purchase food on cash and borrowing grain/ cash from others. About $29.11 \%$ of food secures and $71.43 \%$ of food insecure households bought food on cash whereas, about $24.05 \%$ of food secures and $68.57 \%$ of food insecure households borrowed grain/ cash from others. About $70 \%$ of food secures and $36.71 \%$ of food insecure households sold their livestock as a coping mechanism. On the other hand, $22.78 \%$ of food secure households and $60 \%$ of food insecure households opted to eat less preferred food as a coping mechanism in the study area. The focus group discussions notified that, eating less preferred food was the most commonly practiced coping mechanism. However, in the study area most farmers preferred to produce crops. According to focus group discussion, the respondents preferred to grow the crops which fetch more money as an outcome and in turn buy cheaper or less preferred food commodity in the market. Even for the who received food aid, they received wheat which they decided to sell and bought maize and other staple food preferred in the area of study. In addition to this, as the survey results revealed that households in the study area practiced sales of fire wood, grass and charcoal; participate in petty trade; received food; migrate to other area to work and Children discontinued from their studies in school to seek for employment during food shortage in the study area.

Table 5: Copping strategies employed by household

\begin{tabular}{ccccccc}
\hline Employed Strategies & $\begin{array}{c}\text { Food secure } \\
(\mathrm{N}=79)\end{array}$ & \multicolumn{2}{c}{$\begin{array}{c}\text { Food insecure } \\
\text { Number } \%\end{array}$} & \multicolumn{2}{c}{$\begin{array}{c}\text { Total HHs } \\
\text { Number \% }\end{array}$} & $\begin{array}{c}\text { (149) } \\
\text { Number \% }\end{array}$ \\
\hline Reduce number of meal & 32 & 40.51 & 58 & 82.86 & 90 & 60.40 \\
Reduce quantity of meal & 32 & 40.51 & 55 & 78.57 & 87 & 58.39 \\
Sale of livestock & 49 & 70.00 & 29 & 36.71 & 78 & 52.35 \\
Borrow grain/cash & 19 & 24.05 & 48 & 68.57 & 67 & 44.97 \\
Participation in Pity trade & 39 & 49.37 & 15 & 21.43 & 54 & 36.24 \\
Sale of fire wood and charcoal/grasses & 11 & 13.92 & 30 & 42.86 & 41 & 27.52 \\
Ate less preferred food & 18 & 22.78 & 42 & 60.00 & 60 & 40.27 \\
Receive food aid & 15 & 18.99 & 37 & 52.86 & 52 & 34.90 \\
Purchase food on cash & 23 & 29.11 & 50 & 71.43 & 73 & 48.99 \\
Migrate to other area to work & 7 & 8.86 & 18 & 25.71 & 25 & 16.78 \\
Children discontinued from school & 0 & 0.00 & 5 & 7.14 & 5 & 3.36 \\
\hline
\end{tabular}

Source: Survey result, 2017

\section{Conclusion}

As the study revealed that $53.02 \%$ of the households were food secure while $46.98 \%$ was food insecure. The result of the descriptive statistics indicated that there were significant difference with respect to the mean of age of the household head, family size in AE, dependency ratio and access to the nearest market. The mean in this case is lower for food secure whereas higher for food insecure groups. But, the mean of off-farm/non-farm income, size of cultivated land, livestock ownership excluding oxen, education level of household head and contact with development agents were higher for food secure and lower for food insecure groups. However, there was no significant difference between food secure and insecure households with respect to mean of number of ox/oxen owned.

Moreover, with regard to dummy variable, percentage age of male headed household, chemical fertilizer uses, use of improved seed, cash crop producer and access to credit households were higher for the food secure households group than the food insecure group and also with respect to this variable there were statistically significant difference between food secure and food insecure households at different probability level. The major portions of this study was about the determinants of rural households food security, it has been realized that the determinants of rural households food security were broad, interrelated and varies. These can be addressed by a wide comprehensive intervention from different angles of social aspects. For instance, in this study the credit was found to be significant at one \% probability level and negative relationship with the household food security status. This doesn't mean that credit has no advantage to improve food security, rather it means that the user utilize the credit in the inverse of getting benefit from it like using the credit to buy food consumption and non food consumption. But, at the time of payment of the credit they compensate by selling asset they have and renting land they have which they using for usual crop production. Accordingly, the model results revealed that seven variables were found to be statistically significant.

The coping mechanisms of the households mostly practiced in the study area showed that about $60.40 \%$ 
and $58.30 \%$ of households followed both reducing numbers and quantity of meal to cope with food shortage. The next important coping strategy was purchase food on cash, which by $71.43 \%$ of the sample households. Purchasing food on cash ranked as third important coping mechanisms next to the reduction in the number and quantity of meals. Some coping mechanisms have negative effects on the conservation of finite natural resources, which in long term leads to the problem of food insecurity should be discourage. Lastly, coping mechanisms employed by the households during food shortage were discontinued children to school have also negative effect on development of human capital should be discourage by creating habit of helping short hands family at school level and at society level.

\subsection{Recommendations}

The Possible recommendations that come from the results of the research study can be listed as the following:

$>\quad$ Age of the household head had found significant and negative impact on food security. This means being young household heads increases the likelihood to be food secure than being older household heads. Unlike, sex of headed household had found significant and positive impact on food security. This means being male headed households increases the likelihood to be food secure than being female headed households. Therefore, capacity building in terms of skills for older and female household heads should be given more priority. Moreover, interventions intended to help rural farm households have to give priority to old aged as well as female headed households.

$>\quad$ Family size and dependency ratio were found statistically significant and has negative association with the household food security. The negative sign shows that a probability to be food secures decreases as family size in adult equivalent and dependent ratio increases. As the family size increases the probability of the household to have disguised unemployment increases which would in turn affect the well-being of the household. On the other hands having large family size could expose the family to have high dependency ratio and it is less likely to be food secure or more likely to be food insecure. To offset this, it suggested to facilities the family planning techniques as to reduce average family sizes and therefore the total population and improve on the general well-being of the entire family and besides to family planning it is important to design policies that promote the establishment of operation of off/non-farm income generating opportunities which absorb the available labour force in to work.

$>\quad$ Size of cultivated land was found to be directly related and positively to food security of households in the study area. However, due to the increasing population and diminishing of landholding agricultural production has deteriorated over time. In addition to this, agricultural productions in study area commonly done once in a year due to it depend on erratic and poor rainfall. Therefore, measure like of introduction of water harvesting technology which enables farmers to produce twice in a year should be promoted. In addition to this, strengthening and promoting strategy such as supply of improved seed which is matured in short period of time and moistures resistance seed, use of low cost inputs like natural fertilizer (compost) made from animal dung, plant wood and levies should be promoted to increase production and productivity. As this will allow maximizing earnings from limited land holding.

$>\quad$ Livestock ownership excluding oxen in TLU is positively and significantly associated with the probability of being food secure in the study area. However, due to shortage of pasture land and animal diseases problem the livestock production is no such much good. Even if there is no shortage of animal health in each rural area, due to poor infrastructure such as electricity, poor road and poor water supply the rural farmers not got enough service from animal health services which they might gate. Therefore, the necessary effort should be made to improve the production and productivity of livestock through establishing sustainable and effective forage development program, livestock health delivery system, improve both the breed and livestock management system.

$>\quad$ Distance to market nearest is also a main determinant for food security in the study area. When the distance is very long, the transaction costs such as cost of input, transportation cost and cost of gating information might be higher. It wills also opportunity of gating off/non-farm activity might be lower. Therefore in order to improve food security situation, there is a need to improve road networks and fair management system which follow up price discrimination.

Access to credit was found negatively associated with food security irrespective of the measure used. Therefore, awareness creation on better utilization of credit should be emphasized besides expansion of credit accesses and also if possible it is important to access free interest rate credit due to most of peoples in the study area is Muslim. Through awareness creation regarding formal saving habit which inversely compensates the free interest rate credit has to be undertaken.

\section{Abbreviations}

HH: Households; HHHs: Household Heads; GDP: Growth domestic Product: PSNP: Productive Safety Net Program; SNNPR: Southern Nation Nationality People Region; SSA: Sub-Saharan Africa; UNICEF: United 
Nations International Children's Emergency Fund; WFP: World Food Program.

\section{Acknowledgment}

First, I would like to thank the almighty Allah who helped me to bring this work to the end. Secondly, my heartfelt thanks and sincere appreciation also goes to sample households for their willingness to sacrifice their time and provide genuine responses and; enumerators: for their dedication and effort made to collect quality data. Last but not least, I would like to express my heart-felt thanks, gratitude and appreciation to both my brothers, whom withdrawal from school to give their chance to me as I complete my education due to I am the first born one from them, those are Mohammed Yusuf and Mustafa Yusuf for their generous assistance, moral support and helpful encouragement beside to my father and my mother.

\section{Authors' contribution}

AY designed the study, participated in data collection, processed, analyzed, interpreted the date and wrote the manuscript. EN and SC participated in the data collection supervision and coordinated the field activity. All authors read and approved the final manuscript.

\section{Availability of supporting data}

Not applicable

\section{Ethical approval and consent to participate}

Before starting the work, the study design was explained to rural development and Agricultural extension department Office and Administrative of Meta District for their permission and support. The nature of the study was also fully explained to respondents to obtain consent. Permission was sought from each respondent and they openly and freely answered the questions asked.

\section{Consent for publication}

Not applicable

\section{Competing interests}

The authors declare that they have no competing interests

\section{Funding}

Ministry of Education (MoE) sponsored for research work.

\section{References}

FAO (Food and Agriculture Organization of United Nation). 2015. International Fund for Agricultural Development, World Food Program. 2015. "The State of Food Insecurity in the World 2015. Strengthening the enabling environment for food security and nutrition." FAO, Rome, Italy.

CSA (Central Statistical Agency). 2014. Ethiopia Time Use Survey 2013. Website: WWW.csa.gov.et Ethiopia, Addis Ababa, Ethiopia.

Adugna Eneyew and Wogayehu Bekele. 2012. Determinants of livelihood strategies in Wolaita, Southern Ethiopia. Agricultural Research Review, 1(1): 153-161.

UNDP (United Nations Development Program). 2013. Quarterly key economic and social indicators produced by advisory unit UNDP, Ethiopia. At http://www.et.UNDP.org (updated in August 2014).

UNICEF (Ethiopia Humanitarian Situation Report). 2014. Addis Ababa, Ethiopia. At http://www . UNICEF.org( updated in August 2014).

HRD (Humanitarian Requirements Document). 2016. Ethiopia Humanitarian Situation Report, Addis Ababa, Ethiopia.

Legovini, A. 2006. Impact evaluation in Ethiopia: Evidence on what works and how. Website: http://siteresources.worldbank.org/EXTIMPEVA/Resources/IE.ET.

Gilligan, D.O., Hoddinot, J. and Alemayehu Seyoum. 2009. The impact of Ethiopia's productive safety net program and its linkages. Journal of Development Studies, 45(10): 1684-1706.

Kwadwo Asenso-Okyere, Daniel Ayalew Mekonnen and Elias Zerfu. 2013. Determinants of Food Security in Selected Agro-pastoral Communities of Somali and Oromia Regions, Ethiopia. Journal of Food Science and Engineering, 3(2013):453-471.

MARDO (Meta District Agricultural and Rural Development Office). 2016. Annual report papers, Meta, Ethiopia.

EHZPO (Eastern Hararghe zone planning office). 2001. Eastern Hararghe zone Zonal Atlas, Harar.

MARDO (Meta District Agricultural and Rural Development Office). 2013. Annual report papers, Meta, 
Ethiopia. 15-20p.

Yamane Taro. 1967. Statistics: An Introductory Analysis, 2nd Ed. New York: Harper and Row Lau, L.J. and Yotopoulos, P.A.1972. Profit, Supply and Factor Demand Functions. American Journal of Agricultural Economics, 54:11-18.

Ayalew Yimer . 2003. Identification and Intensity of Food Insecurity and Coping Strategies of Rural Households in North Shoa: The Case of Lalomama. MSc Thesis, Haramaya University, Haramaya, Ethiopia.

Yilma Muluken. 2005. Measuring Rural Household Food Security Status and Its Determinants in the Benishangul Gumuz Region, Ethiopia: The Case of Assosa District. A MSc Thesis, Haramaya University, Haramaya, Ethiopia.

Tewodros Alemayehu. 2007. Analysis of Household Food Security: The Case of Argoba Nationality in Fedis District, East Hararghe Zone of Oromia, Ethiopia. MSc Thesis, Haramaya University, Haramaya, Ethiopia.

Tesfay Kumbi. 2005. Household Food Insecurity in Dodota- Sire District, Arsi Zone: Coping strategies and policy options. MSc Thesis, Haramaya University, Haramaya, Ethiopia.

Fekadu Beyene and Mequanent Muche. 2010. Determinants of Food Security among Rural Households of Central Ethiopia: An

Empirical Analysis. Quarterly Journal of International Agriculture (4)49: 299-318

Aschalew Feleke. 2006. Determinants and dimensions of household food insecurity in Dire dawa Ethiopia. MSc Thesis, Haramaya University, Haramaya, Ethiopia.

Guled Abdullahi. 2006. Food Insecurity and Copping Strategies of Agro-pastoral Household in Awbare District, Somali Region, Ethiopia. MSc Thesis, Haramaya University, Haramaya, Ethiopia.

Fikadu Tefera and Tewodros Tefera. 2014. Determinants of Households Food Security and Coping Strategies for Food Shortfall in Mareko District, Guraghe Zone Southern Ethiopia. Journal of Food Security, 2(3): 92-99. Doi: $10.12691 / \mathrm{jfs}-2-3-4$. 